\title{
The Principle of the Causal Openness of the Physical
}

\author{
Daniel von Wachter*
}

Received: 16 July 2018 / Accepted: 3 December 2018

\begin{abstract}
The argument from causal closure for physicalism requires the principle that a physical event can only occur through being necessitated by antecedent physical events. This article proposes a view of the causal structure of the world that claims not only that an event need not be necessitated by antecedent events, but that an event cannot be necessitated by antecedent events. All events are open to counteraction. In order to spell out various kinds of counteraction I introduce the idea of 'directedness.'
\end{abstract}

Keywords: Causal closure; determinism; free will; miracles.

\section{Introduction: the principle of causal closure}

(1.1) The Principle of Causal Closure (PCC) expresses a substantial conviction about causality and about everything that happens. Contrary to PCC, in this article I shall defend the 'Principle of the Causal Openness of the Physical' (PCO). I shall proceed by addressing the following points:

- Note how influential PCC has been.

- Which version of PCC is required for an argument against the existence of physical events that have a non-physical cause?

* International Academy of Philosophy in the Principality of Liechtenstein

International Academy of Philosophy in the Principality of Liechtenstein, FürstFranz-Josef-Str. 19, FL-9493 Mauren, Liechtenstein

$\bowtie$ epost@von-wachter.de

Website: http://von-wachter.de

(C) The Author. Journal compilation (c) The Editorial Board, Organon F.

This article is distributed under the terms of the Creative Commons Attribution-NonCommercial 4.0 International Public License (CC BY-NC 4.0). 
- State the Principle of Causal Openness.

- Relate PCO to the phenomenon of superposition.

- Introduce the idea of directedness and relate it to PCO.

(1.2) Many believe that PCC constitutes a strong reason for believing that there are no souls interacting with the body and that there are no divine interventions. Thus David Papineau:

Over the latter half of the last century English-speaking philosophy became increasingly committed to naturalistic doctrines. Much of this naturalistic turn can be attributed to the widespread acceptance of the thesis that the physical realm is causally closed. (Papineau 2009, 53)

[I]t was the empirical evidence for causal closure that persuaded philosophers to be physicalists. Once mid-century physiological research had established that all physical effects had physical causes, even in bodies and brains, philosophers quickly figured out that general physicalism followed. (B. G. Montero and Papineau 2016, 188)

Jaegwon Kim formulated PCC in the following way, which some call 'Twoway Causal Closure' (TCC) (Montero 2003, 175):

If you pick any physical event and trace out its causal ancestry or posterity, that will never take you outside the physical domain. That is, no causal chain will ever cross the boundary between the physical and the nonphysical. (Kim 1998, 40)

(1.3) Unless the words 'never' and 'will ever' are taken to include possible worlds or the word 'cannot' is added, this formulation says only:

No past and future physical events have nonphysical causes.

Let us call this nonmodal version of PCC 'NMPCC.'

Can NMPCC be used for an argument for physicalism? No, it requires a modal version. Imagine that there are no nonphysical objects. In that case NMPCC is true. But how can one then know that NMPCC is true? By investigating the evidence for the existence of souls and of God and by finding that there is little evidence or by finding that there is evidence 
against the existence of souls or God. By this investigation one can know the truth of NMPCC, but NMPCC provides no reason for believing that no physical events have nonphysical causes. There is no argument from NMPCC to physicalism here, because the belief in physicalism justifies the belief in NMPCC, but the belief in NMPCC cannot be justified without belief in physicalism.

(1.4) The physicalist who wants to use PCC in defence of his view needs a modal version of PCC. And indeed that is what Kim and the other proponents of PCC mean. In another book Kim uses the formulation quoted above but adds: 'If $x$ is a physical event and $y$ is a cause or effect of $x$, then $y$ too must be a physical event' (Kim 1996, 147). In a more recent book he formulates PCC as 'If a physical event has a cause at $t$, then it has a physical cause at t" and elucidates this by saying: "There can be no causal influences injected into the physical domain from outside' (Kim 2005, 16).

(1.5) Papineau states PCC using the notion of a 'sufficient cause.'

Every physical effect has a sufficient physical cause. (Papineau 2009, 53)

This is nearly identical to determinism, which is usually defined as the claim that 'Every event has a preceding sufficient cause.' 'Sufficient' is usually taken to be equivalent to 'necessitating,' so that Papinau's PCC amounts to Thomas Hobbes's formulation of determinism: 'All the effects [events] that have been, or shall be produced, have their necessity in things antecedent. $^{2}$

(1.6) What does the term 'sufficient cause' in Papineau's PCC mean? If it meant only that there is all that is required ${ }^{3}$ to cause the event, then

1 This version of PCC 'does not by itself exclude nonphysical causes [...] of physical events' but only if the principle of causal exclusion is added: 'If an event e has a sufficient cause $\mathrm{c}$ at $\mathrm{t}$, no event at $\mathrm{t}$ distinct from $\mathrm{c}$ can be a cause of a (unless this is a genuine case of causal overdetermination)' (Kim 2005, 17).

2 '[... quaecunque producta vel erunt vel fuerunt, necessitatem suam in rebus antecedentibus habuisse' (De corpore, 9.5).

3 John Bramhall $(1655,172)$ criticised Hobbes for confusing 'sufficient' in the sense of 'enough' with 'necessitating.' Christian August Crusius (1743) objected to Leib- 
Papineau could simply say 'Every physical effect has only physical causes' or 'Every physical effect has only non-probabilistic physical causes' (although this is in conflict with quantum mechanics). This statement can be justified only by defeating all the argunents for the existence of nonphysical objects, that is, it cannot be justified without presupposing physicalism.

The defenders of PCC who use PCC for an argument against interactionist dualism must mean by a 'sufficient physical cause' 'a physical state of affairs that alone suffices to determine the effect.' ${ }^{\text {' }}$ So they use 'sufficient cause' equivalently to 'necessitating' or 'determining.' Some philosophers, in particular Leibniz, believed that it is a metaphysical principle that everything that exists has a determining reason; one that entails or necessitates "why it should be so and not otherwise. ${ }^{5}$ They believed that it is impossible that something exists that was not determined. PCC makes this more specific, claiming that an event has to have a determining preceding cause. Such a cause makes it impossible for an immaterial object to prevent the effect, and an event that had such a cause could not have been prevented by an immaterial object once the cause had occurred. Determining causes exclude interventions. That is the idea behind the argument from PCC. It is not just the claim that there are no nonphysical causes of physical events but the claim that the physical is causally 'closed.'

(1.7) Belief in PCC has been influential for longer than, as Papineau suggests, since 1950. Consider Hobbes's line of reasoning (stated in my words): ${ }^{7}$ If an event occurs, then its cause was complete ('entire') and sufficient, otherwise it would not have occurred. If a cause is complete, then the effect has to follow, otherwise the cause is not complete. A complete

niz's 'Principle of Sufficient Reason' that Leibniz should have called it 'the principle of the determining reason.'

4 (B. Montero 2003, 174). Menzies (2015) argues that the argument from PCC is invalid if 'causal sufficency' is interpreted as 'nomological sufficiency' and 'causation' as 'counterfactual difference-making.'

5 Leibniz, Monadology, § 32.

${ }_{6}$ Various versions of PCC are discussed by Gibb (2015, 628), Lowe (2008, chap.

2), and B. Montero (2003, 174).

7 (Hobbes 1655, chap. 9), similarly (Hobbes 1654). 
cause is a sufficient cause, and a sufficient cause cannot but produce the effect; the effect cannot but follow it. Hence, every event is necessitated by preceding events. Hobbes applied this to free will and concluded:

$[\mathrm{T}]$ hat ordinary definition of a free agent, namely, that a free agent is that, which, when all things are present which are needful to produce the effect, can nevertheless not produce it, implies a contradiction, and is nonsense; being as much as to say, the cause may be sufficient, that is to say, necessary, and yet the effect shall not follow. (Hobbes 1654, § 32)

Determinism was extremely influential in Western Europe through Hobbes, Leibniz, and Christian von Wolff. Although Immanuel Kant did not affirm it for the 'things in themselves' because he considered free will to be undeniable, he spread determinism by claiming that the 'principle of causality' is a priori, it is a principle of thought that cannot be denied:

Everything that happens is at all times determined before through a cause according to constant laws. ${ }^{8}$

Although there have always been critics of determinism, these are much less known today than the determinists. Especially in the $19^{\text {th }}$ century in Germany, many considered determinism to be the hallmark of rationality and of science. Those who endorsed it were declared to be part of the 'Enlightenment.' From around 1780 onwards in Germany some popular writers declared Wolff and Kant to be representatives of 'the Enlightenment,' Hobbes and Leibniz were considered to be precursors of the Enlightenment. To those who accepted determinism, the human soul interacting with the body, free will, and divine interventions, which had previously been accepted by most European thinkers, were considered to be not rational and not up to date. Belief in determinism led many Christian theologians and churches to give up belief in miracles. Thus determinism and PCC is a philosophical doctrine that changed the world.

(1.8) Let us formulate PCC in a way that is clear and serves the purpose of the physicalist:

8 'Alles, was geschieht, [ist] jederzeit durch eine Ursache nach beständigen Gesetzen vorher bestimmt.' (Prolegomena, § 15) 
There cannot be a physical event that is not necessitated by preceding physical events. (NPCC)

In other words, a physical event can only occur by being necessitated by preceding physical events. That event $\mathrm{S}_{2}$ at time $\mathrm{t}_{2}$ was necessitated by event $S_{1}$ at time $t_{1}$ means that it was impossible that $S_{1}$ occurs (i.e. an event happens that is exactly like $\mathrm{S}_{1}$ ) but $\mathrm{S}_{2}$ does not. Unless indicated otherwise, I shall mean by 'PCC' always 'NPCC.' NPCC is what the defenders of PCC mean or should mean, because the nonmodal versions of PCC can only be justified by an investigation of the evidence for nonphysical objects.

(1.9) If NPCC is true, we might well be able to know it and use it as a powerful argument against interactionist dualism and against the existence of divine interventions. We know some modal truths through insight, through thinking about our experience, or through some special kind of experience. This way we can then know something about the individual cases about which the modal truth says something without investigating them individually. For example we know that it is impossible that $x$ has a cause that is later than $x$. This way we know that there are no cases of backward causation without having to investigate any evidence for alleged cases of backward causation.

If we could know NPCC, that would be a great philosophical success. It would mean not only that we can know something as substantial as that through philosophical reasoning, but that we could know it without considering the evidence. It would mean that we can know that we have no soul (that interacts with the body) without considering the evidence and the various arguments for and against it, and that we can know that there are no divine interventions without considering the evidence for the various divine interventions in which people believe. It would be a shortcut argument, a knock-out argument. While Papineau thinks that PCC is supported through physics, Hobbes and Kant believed that determinism can be known a priori, just by thinking about how an event can occur and about causality.

(1.10) I shall now propose a principle, which I call the Principle of the Causal Openness of the physical (PCO), which contradicts PCC. Causality as we know it is not as PCC describes it. The physical is causally open to non-physical intervention. 


\section{Causal openness}

(2.1) The principle which I want to defend in opposition to PCC and which I call the Principle of the Causal Openness of the Physical (PCO) is:

Physical causes are open to cooperation and to intervention.

(2.2) Openness to cooperation: Each event is so that there can be an additional event in conjunction with which it can cause something different. More precisely:

If event $S_{1}$ (at time $t_{1}$ ) was the complete physical cause of event $S_{2}$ (at time $t_{2}$ ), then in addition to $S_{1}$ an event at $t_{1}$ could have existed in cooperation with which $S_{1}$ could have caused an event at th that does not contain $S_{2}$.

(2.3) Openness to intervention: Arguments from PCC against non-physical causes assume that a complete physical cause necessitates its effect and therefore excludes that something non-physical impedes the causing. Contrary to this, PCO states that all causes are liable to intervention:

Even if event $S_{1}$ (at time $t_{1}$ ) was the complete physical cause of event $S_{2}$ (at time $t_{2}$ ), then it was possible that $S_{1}$ occurs but something prevents $S_{2}$.

Cooperation and intervention are two ways how an event can be prevented from causing what it would have caused on its own, had nothing else acted on it or on what follows. They are two ways of counteraction. Cooperation is done by events that are synchronical with the event in question. Intervention is done at some time later, and it can be done by either a physical event or by whatever other kinds of things exist.

(2.4) One important negative implication of PCO is:

No event can necessitate a later event. ${ }^{9}$

9 I have defended this claim also in (Wachter 2009, § 5.10) and (Wachter 2012). That causes do not necessitate their effects is also argued by Mumford and Anjum (2011, chap. 3). Gibb (2015, § 2) explains why according to the powers theory of causation not all causes are sufficient. This is a weaker claim than mine. 
Thus, not even non-probabilistic event causes necessitate their effects. By 'later' I mean that the beginning of the second event is no earlier than the end of the first event. If we are speaking about events occurring at certain points of time, then I mean that the second event occurs at a later point of time.

(2.5) I am assuming in this article that the laws of nature do not or cannot change. So the reason wherefore I claim that no event necessitates a later event is not that the laws can change. Further, I am assuming that if there is a God, he continues to sustain things with their causal powers in being. So the reason wherefore I claim that no event necessitates a later event is not that God may stop sustaining things.

(2.6) Applied to processes, PCO implies:

Causal processes are stoppable.

(2.7) Let me elucidate the counterfactual and modal claims that I have used. By saying that 'event $x$ necessitated event $y$ ' I mean: it could not have happened that although $x$ occurs $y$ does not. The occurrence of $x$ is incompatible with the non-occurrence of $y$. Or: the scenario in which $x$ (or an event exactly like $x$ ) occurs but not $y$ is not possible. Speaking more extensionally: In every possible world in which $x$ (or an event exactly like $x$ ) occurs $y$ occurs too.

(2.8) By saying 'it was possible that $\mathrm{S}_{1}$ occurs but something prevents $\mathrm{S}_{2}$ ' I mean that the occurrence of $\mathrm{S}_{1}$ is compatible with something preventing $\mathrm{S}_{2}$ and thus $\mathrm{S}_{2}$ not occurring. Extensionally speaking: In some possible worlds, $\mathrm{S}_{1}$ (or an event exactly like $\mathrm{S}_{1}$ in the actual world) occurs but $\mathrm{S}_{2}$ does not because something prevents it.

(2.9) I am assuming that being possible is something different from being consistent (i.e. being not self-contradictory), and being necessary is something different from being analytic. When I say ' $x$ necessitated $y$ ' I do not mean that the description of $x$ is contradictory to the negation of the description of $y$. For every description of something there is the question whether the existence of something to which the description applies is possible. For self-contradictory descriptions, like 'a married bachelor,' this question does not arise. Modal questions arise with respect to consistent descriptions. That the predicates $\mathrm{P}$ and $\mathrm{Q}$ are contradictory means that in 
the relevant language the meanings of ' $\mathrm{P}$ ' and ' $\mathrm{Q}$ ' are such that ' $\mathrm{P}$ ' is used in order to say about something, among other things, that it is not $\mathrm{Q}$ (or vice versa). That the existence of something that is $\mathrm{P}$ and $\mathrm{Q}$ is impossible means that, while ' $\mathrm{P}$ ' and ' $\mathrm{Q}$ ' are not contradictory, the properties to which ' $\mathrm{P}$ ' and ' $\mathrm{Q}$ ' refer cannot be had by one thing at the same time; they are not combinable. We have the two different words 'contradictory' and 'impossible' for a good reason. They refer to very different phenomena. ${ }^{10}$

For our case here that means that on the one hand I am not saying that, for example, ' $\mathrm{S}_{1}$ necessitates $\mathrm{S}_{2}$ ' is contradictory, and on the other hand I am not just saying that ' $\mathrm{S}_{2}$ was prevented although $\mathrm{S}_{1}$ occurred' is consistent.

(2.10) As PCC is used against substance dualism, I want to specify what an interaction between the soul and the body and thus a violation of PCC would be like. In my view, in an action (in my view not just in a free action but in any action) the agent brings about an event directly in the sense that it is not the result of a causal process and thus has no preceding cause but occurs through an action. I call such an event a choice event. This bringing about directly is not a kind of process causation, it is a phenomenon sui generis. It is not obvious that only souls or God can bring about choice events. Someone who holds that there are no souls could hold that material persons can bring about choice events. But if there are souls or bodiless persons, then they can bring about choice events. I am inclined to think that this is the only way immaterial objects cause physical events. The soul can bring about a property change (perhaps the firing of a neuron) in the brain which has no preceding cause but is due to the soul. Similarly, God, while he is sustaining the universe, might bring about events in the universe directly so that they have no preceding complete cause. Perhaps only he can bring about physical events which have no material cause at all. He can bring about as choice events in the physical world not only property changes, but he can bring about entirely new things. The relevance of all this for this article is that PCO implies that the physical world is open to choice events.

10 For a defence of this view of possibility see (Wachter 2009, chap. 3). 


\section{Superposition}

(3.1) Before I present in defence of PCO a more detailed account of causal processes, I want to point out that PCO is suggested by the phenomenon of superposition. Newtonian forces can be superpositioned and can be calculated by vector addition. Every force can be combined with other forces. Every force can be counteracted by another force. If various forces are acting on a body, then they have the same effect as if only the force that is their sum acted on the body.

(3.2) If body $\mathrm{B}$ with mass $\mathrm{m}$ is exerting a gravitational force $F_{B}$ on body $\mathrm{A}$, which also has mass $\mathrm{m}$, and nothing else is acting on the body, then A accelerates with $a=F_{B} / m$. But if there are more forces acting on A, then it moves in a different way. For example, there could be a body opposite of $\mathrm{C}$ with mass $\mathrm{m}$ so that $\mathrm{A}$ does not accelerate at all because the gravitational forces exerted by $\mathrm{B}$ and $\mathrm{C}$ cancel out each other. $F_{B}$ contributes to how it moves, but it does not determine how A moves.

(3.3) If body $\mathrm{A}$ was accelerated by body $\mathrm{B}$ through the gravitational force $F_{B}$, then A's movement at time $\mathrm{t}_{2}$ was caused partly by $\mathrm{B}$ at $\mathrm{t}_{1}$. Let us call the effect, A's movement at time $\mathrm{t}_{2}$, ' $\mathrm{S}_{2}$ ' and its complete cause at $\mathrm{t}_{1}$ ' $\mathrm{S}_{1}$.' $\mathrm{S}_{1}$ led through a causal process to $\mathrm{S}_{2}$. Had there been an additional force acting on A, A would have moved differently at $\mathrm{t}_{2}$ and already right after $\mathrm{t}_{1}$. Hence $S_{1}$, the complete cause, caused but did not determine (necessitate) $S_{2}$. That is, it could have happened that although $\mathrm{S}_{1}$ occurs something prevents $\mathrm{S}_{2}$. This is what PCO says about this case. Not only something after $t_{1}$ and before $t_{2}$ could prevent $S_{2}$ but also something at $t_{1}$ could prevent $\mathrm{S}_{2}$, by forming a cause together with $\mathrm{S}_{1}$ which then causes something other than $\mathrm{S}_{2}$. States of affairs can be counteracted by cooperating states of affairs.

It is true that the following was impossible: $\mathrm{S}_{1}$ occurs, $\mathrm{S}_{2}$ does not occur, and nothing prevented $\mathrm{S}_{2}$. It is also true that 'given that $\mathrm{S}_{1}$ occurred and nothing prevented $\mathrm{S}_{2}, \mathrm{~S}_{2}$ had to occur.' But the sentence ' $\mathrm{S}_{1}$ determined $\mathrm{S}_{2}$ ' cannot reasonably be understood as saying just this. Note that this true statement, 'Given that $\mathrm{S}_{1}$ occurred and nothing prevented $\mathrm{S}_{2}, \mathrm{~S}_{2}$ had to occur,' is of no use to an argument against interactionist dualism or against divine interventions, because it leaves open that a soul or God could prevent 
$\mathrm{S}_{2}$. The sentence ' $\mathrm{S}_{1}$ determined $\mathrm{S}_{2}$ ' in the sense which is required for an argument against interactionist dualism is false.

(3.4) Someone might want to reply: ' $\mathrm{S}_{1}$ determined $\mathrm{S}_{2}$ given the circumstances.' The 'circumstances' should refer to certain states of affairs that obtained at $t_{1}$ in addition to $S_{1}$. However much you include in these circumstances, it will always be true that the state of affairs that consists of $S_{1}$ plus the circumstances did not necessitate $S_{2}$, because the state of affairs that consists of $S_{1}$ and the circumstances is compatible with the existence of some further state of affairs which prevents $\mathrm{S}_{2}$. If one replaces 'given the circumstances' by 'given that nothing else was acting on $\mathrm{S}_{1}$ ' (I call that the 'no-further-causes clause'), it is still not true that $\mathrm{S}_{1}$ determined $S_{2}$, in the sense of ' $S_{1}$ necessitated $S_{2}$,' because $S_{1}$ is compatible with the existence of something that prevents $\mathrm{S}_{2}$. What is true is that the following is impossible: $\mathrm{S}_{1}$ occurs, and $\mathrm{S}_{2}$ does not occur, and nothing prevented $\mathrm{S}_{2}$.

(3.5) Finally, someone might want to hold that 'It is impossible that $\vec{F}=\sum_{i=1}^{n} \vec{F}_{i}$ is the resulting force acting on $\mathrm{A}$ at $\mathrm{t}_{1}$ but $\mathrm{A}$ does not accelerate (at and after $\mathrm{t}_{1}$ ) with $a=F / m$.' If 'force' here were be understood as just any action on A, then the statement would be true. But if 'force' refers just to forces in the sense used in physics - that is, to forces which obey $a=F m$, which are exerted by physical objects, and which are described by laws of nature - then it does not include the action by souls or by God. With that the statement would have the implications that the physicalist desires, but it cannot be justified and is false, because an agent can counteract the resulting force. As mentioned above, in an action the agent brings about an event directly in the sense that it has no preceding cause but is due to the agent. It is to be investigated whether such events exist, but I see no reason for claiming that they are impossible. In any case, even if such actions on physical objects were impossible, that would not be because somehow the physical is closed or because physical causes exclude the intervention by immaterial agents. So this would not support the argument from causal closure. Physical events are open to cooperation and to counteraction. 


\section{Directions}

(4.1) Now I want to introduce some ideas and concepts with which we can understand and describe causal openness better. Imagine a rolling billiard ball A hitting billiard ball B at time t. A's hitting B causes B's movement at a certain time $t_{3}$ after $t_{2}$. That is a clear example of causation, more specifically of 'event causation' or, as I prefer to call it, of 'process causation.' It is also quite clear that it is true to say that A's movement at a certain time $t_{1}$ before $t_{2}$ caused B's movement at a certain time $t_{3}$ after $t_{2}$. A's rolling between $t_{1}$ and $t_{2}$ is a clear example of a causal process.

(4.2) Allow me to comment briefly on the method of our philosophical investigation. While some assume that in philosophy we investigate only concepts, I now invite you to think not about concepts, nor about possible counter-examples to certain definitions, nor about the meaning of 'cause' or 'causal process,' but about typical cases of event causation and causal processes and about what is going on in them. It seems to me that philosophers when they investigate causation are often misled because they think about the concept of causation instead of thinking about what a typical case of causation is like. The concept of a cause subsumes a variety of cases. The assumption that all concepts have a definition of the standard form, consisting of 'necessary and sufficient conditions,' is questionable. At any rate, the task of finding the correct definition of causation which captures all those and only those cases, discussing all those peculiar counter-examples that have been advanced in the literature against the various definitions that have been proposed, is rather different from the task of describing certain cases of causation. I ask the reader now to think not about concepts, not about possible counter-examples to certain definitions nor about what we mean by 'cause' or by 'causal process,' but about what typical cases of causation and of causal processes are like and what is going on there. Causal processes are a phenomenon that we find in the world. What they are we can know only through experience and through thinking about causal processes.

(4.3) Imagine that at time $\mathrm{t}_{2}$ ball $\mathrm{A}$ hits ball $\mathrm{B}$. Through the collision the process of the rolling of $\mathrm{A}$ from $\mathrm{t}_{2}$ does not continue in the direction into which it was heading before $t_{2}$. In this sense it was stopped. We can 
see all the time that causal processes are stopped. What follows is obvious but was not recognised by Thomas Hobbes (see above pp. 43-44): At least some causal processes can be stopped. They are stoppable.

(4.4) All physical causal processes are stoppable; non-stoppable processes, as posited by Hobbes, are impossible. We will consider in more detail what the stopping can consist in, but here is a first consideration in defence of this: Small and medium-sized processes can be stopped by processes of the same kind. A billiard ball can be stopped by a billiard ball, a tidal wave can be stopped by a tidal wave, a planet can be stopped by a body of a similar size. Is also the process of the whole universe stoppable? A bigger process requires something bigger, more powerful to stop it, but the size of a process does not influence its modal properties. If small physical processes, like a rolling billiard ball, are stoppable, then big ones of the same kind are also stoppable. Of course, if there is nothing besides the universe, then there is nothing that could stop the process that is constituted by the universe, but nevertheless it is stoppable. The statement 'There is nothing besides the universe' implies that there is nothing that could stop it, but the things and events that constitute the process of the universe are compatible with the existence of additional objects, either material ones or immaterial ones, which, if powerful enough, could stop the universe.

(4.5) A and B can also be considered together as constituting one process. The process that at $t_{1}$ includes $A$ and $B$ is not stopped at $t_{2}$, but it contains two processes that collide at $\mathrm{t}_{2}$ and are thereby stopped. We can draw the boundaries of processes in various ways. What is not arbitrary though is what belongs to the process at $t_{1}$ which led to the rolling ball $\mathrm{A}$ at $t_{2}$. For a certain event $S_{2}$ at $t_{2}$ it is a fact of the matter what at $t_{1}$ belonged to the event $S_{1}$ which was the stage of the process that led to $S_{2}$ at $t_{2}$ and thus is at $t_{1}$ the complete cause of $\mathrm{S}_{2}$.

(4.6) There are connections between the stages of a causal process. Its stages are not as unconnected as the Moon at $t_{1}$ is unconnected to the Pleiades at $t_{2}$. Rather, the process has a direction. It cannot stop without something stopping it. It cannot stop or change its direction by chance.

(4.7) The process has a direction at each of its stages. A stage of a process we can call an 'event' or a 'state of affairs.' I often use the term 'event' instead of 'state of affairs' just because it is shorter. A stage of a process 
consists of certain properties being at certain things or places at a certain time. So we specify an event or state of affairs by saying which properties at which place or thing at which time we mean. So the event $S_{1}$, which is the stage of the process at $t_{1}$ (or at an interval ending at $t_{1}$ ), has a direction. It is directed towards $\mathrm{S}_{2}$ at $\mathrm{t}_{2}$. We can call the state of affairs in virtue of which the direction exist its 'basis.' I use the terms 'direction' and 'directedness' equivalently. Thus we can say:

$S_{1}$ at time $t_{1}$ is the basis of a directednes ${ }^{11}$ towards $S_{2}$ at time $t_{2}$.

If $\mathrm{S}_{1}$ is the basis of a directedness towards $\mathrm{S}_{2}$ at $t_{2}$, then $\mathrm{S}_{1}$ is also the basis of a directedness towards certain events at times between $t_{1}$ and $t_{2}$. Two directednesses with the same basis are necessarily pointing in the same direction. We can call $\mathrm{S}_{1}$ 's directedness towards $\mathrm{S}_{2}$ at $\mathrm{t}_{2}$ 'base-identical' to $\mathrm{S}_{1}$ 's directedness towards a certain event $S$ ' at a time t' that is between $t_{1}$ and $\mathrm{t}_{2}$.

(4.8) Saying that 'the directedness based on $S_{1}$ at $t_{1}$ towards $S_{2}$ at $t_{2}$ was realised' means that things followed that directedness until $\mathrm{S}_{2}$ and that thus $\mathrm{S}_{2}$ occurred. $\mathrm{S}_{1}$ was then at $\mathrm{t}_{1}$ the complete cause of $\mathrm{S}_{2}$. $\mathrm{S}_{1}$ led to $\mathrm{S}_{2}$. $\mathrm{S}_{2}$ was a result of the process coming from $\mathrm{S}_{1}$. $\mathrm{S}_{1}$ was a complete stage of the process coming from $\mathrm{S}_{1}$. A causal process is the realization of a directedness.

(4.9) A causal process is stopped if something brings about an event that is incompatible with an event towards which the process was directed. By calling two directions 'conflicting' I mean that they are directed towards incompatible events at some time. That two directions are non-conflicting means that the events towards which they are directed are never incompatible. That two directions are non-conflicting until time $t$ means that they are not directed towards incompatible events before t. A resulting directedness is one that is for some time not conflicting with another directedness.

11 Instead of the term 'directedness' in earlier publications I used the term 'tendency' and called the theory the 'tendency theory' (Wachter 2009, 2003). I am now using the term 'directedness,' although it is more clumsy, because I found that most readers associate 'tendency' with being probabilistic. 
(4.10) As we could take any portion of matter to be a 'thing,' we could take any properties at any locations at one time to be an event. Every physical event is the basis of a directedness. Any number of physical events at the same time can be taken to be one event. The whole event as well as the composite events each have their direction. The directednesses of the composite events constitute the directedness of the whole event. As long as constituting non-overlapping events are non-conflicting, the direction of the whole event is the sum of the directions of the constituting events. If an event is constituted by events whose directions are conflicting, then one of the directions could trump the other, or together they constitute a new direction.

(4.11) Now we can spell out how an effect can be prevented, as mentioned in this sibling of PCO: 'If event $S_{1}$ (at time $t_{1}$ ) was the complete physical cause of event $S_{2}$ (at time $t_{2}$ ), then it was possible that $S_{1}$ occurs but something prevents $\mathrm{S}_{2}$.' There are at least three ways how it could be that A occurs but B does not:

1. By cooperation: There could exist at $t_{1}$ an event which together with $\mathrm{S}_{1}$ is not directed towards $\mathrm{S}_{2}$.

2. By intervention through a physical process: It is compatible with the occurrence of $\mathrm{S}_{1}$ that there is a physical process which is directed towards an event at some time between $t_{1}$ and $t_{2}$ which is incompatible with an event towards which $\mathrm{S}_{1}$ was directed. This would prevent $\mathrm{S}_{2}$.

3. By intervention through a person: $\mathrm{S}_{1}$ does not exclude that there is a person who, at some time between $t_{1}$ and $t_{2}$, brings about a choice event that is incompatible with an event towards which $\mathrm{S}_{1}$ was directed. This would prevent $\mathrm{S}_{2}$.

(4.12) Thus far I have introduced only non-probabilistic directednesses, which we can also call 'unambiguous directednesses.' A non-probabilistic directedness is one that necessarily will be realised if nothing counteracts. In other words, one for which the following is impossible: it is not realised although nothing counteracts. A probabilistic directedness, on the other hand, is one that can fail to be realised just by chance; that is, one for which it is possible that it is not realised although there is nothing that counteracts. 
A probabilistic directedness can have a strength that can be described with a number between 0 and 1 , corresponding to the probability of the realisation if nothing else is acting on the object. So that a directedness has strength 1 does not mean that it is necessarily realised, but only that is realised if nothing counteracts. Probabilistic directednesses can be disjunctive, that is, they can be towards either $\mathrm{K}$ or, instead, $\mathrm{L}$ occurring at $\mathrm{t}_{2}$. Instead of 'unambiguous' one could use the term 'deterministic,' but philosophers usually use this term in the sense of 'necessitating.'

(4.13) Let me add a hypothesis concerning general facts about directednesses. I suspect that it is impossible that two events are alike but have different directions. Like events (i.e. events that are exactly similar) have like directions. By this I mean, as indicated above (pp. 47-48), that it is not contradictory but impossible that two events are alike but have different directions.

(4.14) With the notion of 'directedness' or 'direction' we can formulate a philosophical theory of laws of nature:

A law of nature states that events of a certain kind are the bases of directednesses of a certain kind. ${ }^{12}$

(4.15) If one accepts the claim that physical events are necessarily necessitated by preceding physical events and adds the thesis that similar events necessitate similar events (events of type $x$ necessarily necessitate events of type $y$ ), then one arrives at the thesis, which I call the regularity thesis, that there are regularities of succession of the form 'every event of type $x$ is followed by an event of type $y$ ' and that every event is an element of such a regularity of succession. Some accept the regularity thesis not because they assume that physical events are necessarily necessitated but because they assume that it is entailed by the laws of nature, or because they believe to observe its truth.

The regularity thesis entails causal closure (at least the nonmodal version), because the physical effect of an immaterial cause would be a physical event instead of which another physical event would have occurred if the

12 For a detailed defence of this theory of laws, see (Wachter 2009, chap. 6). There I used the term 'tendency' instead of 'directedness.' 
intervention had not occurred. More precisely, a physical effect of an immaterial cause would be a physical event $z$ which follows an event $x$ which, had it not been counteracted, would have caused $y$, while $y$ is incompatible with $z$. Those $x$-like events which are not counteracted cause $y$-like events. So if $z$ is the physical effect of an immaterial cause, then some $x$-like events are followed by $y$-like events while others are not.

The directedness theory undermines the regularity thesis. If event $\mathrm{S}_{1}$ was the complete cause of event $\mathrm{S}_{2}$, then it is possible that some of the events that are like $S_{1}$ do not cause an event like $S_{2}$ because something prevents that through cooperation or through intervention; that is, either because there is some event at the same time together with which the $\mathrm{S}_{1}$ like event does not have a direction towards an $\mathrm{S}_{2}$-like event, or because something - a physical process or an immaterial cause -intervenes in the process which without the intervention would have led to an $\mathrm{S}_{2}$-like event. Like events have like directions - in my view even necessarily - but like events do not need to have like effects. What is true is only that all S1-like events that are not counteracted (through cooperation or through intervention) cause $\mathrm{S}_{2}$-like events. ${ }^{13}$

(4.16) The word 'cause' is useful in ordinary language, but it lumps together quite different phenomena. I have suggested that if event $S_{1}$ at $t_{1}$ is the basis of a directedness towards event $S_{2}$ at $t_{2}$ and if that directedness is realised - that is, nothing stops the process - then it is true to say 'A caused B.' But we also make causal statements which are true but not of this type. For example: 'Because there was no dike, the field was flooded,' 'Because the wood was wet, it did not catch fire,' 'John caused the breaking of the window by throwing a stone into it,' 'Because John had not turned off the stove, a fire broke out in the kitchen.' Besides that, we tend to call only the last event which gets a process going the 'cause' of the event towards which the process leads. We call the spark the cause of the explosion. The gas in the room we might not call 'cause'-philosophers sometimes call it a 'condition' - of the event, although it is as much a part of the basis of the process as the spark is. Further, we generally do not call the ball A at

13 If a complete cause is big in the sense that it involves many things, then the regularity is more likely to exist, because there will be few or no other instances of events that are exactly like this cause. 
time $\mathrm{t}_{1}$ the cause of the ball $\mathrm{A}$ at time $\mathrm{t}_{2}$ (endurance), although, in my view, there is the same kind of process connecting the two stages of the same, enduring thing as there is in the case of the rolling ball. So there are many more cases which we call causation besides causation through processes as I described it.

On the other hand, while directedness is the mechanism of process causation, most directednesses are not realised, because they conflict with other directednesses, and therefore are not cases of causation. Most directednesses contribute to what happens by contributing to some resulting directedness that is realised but they are not realised. For example, the book on my desk is the basis of a directedness towards the moving downwards (i.e. towards being at certain positions at certain later times), but this directedness is not realised because the desk is in the way. 'Cause' is a success term in the sense that of the existing directednesses it singles out only those that are realised. So directedness is more fundamental and more widespread than causation is.

(4.17) Newtonian forces are an example of directednesses: ${ }^{14}$ That there is a force acting on a certain body means that there is a directedness towards the body being at certain positions at certain later times. For forces we know precisely how they can be in superposition and how they behave when they conflict with each other. Every force can be counteracted by another force. If it is, then it does not accelerate the body in the way in which it would have done had it not been counteracted and had it been the resulting force. Every force can join forces with other forces. If two forces, for example two gravitational forces, are acting on a body then there is a resulting force whose direction and strength can be calculated using vector addition. ${ }^{15}$ All the forces that are acting on a body compose the resulting force.

14 This presupposes that component forces are real, as argued by Massin (2017) and Mumford and Anjum (2011, § 2.7). Schrenk (2010, § 5) suggested that 'Maybe dispositional powers can, at least metaphorically, be compared to Newtonian forces: a force pushes an object into a certain direction but it does not necessitate a movement, for other forces might well interfere.'

15 Mumford and Anjum (2011, chap. 2) argue that causes can be 'modelled' as vectors. They spell out causation in terms of powers and dispositions, but their theory has much in common with my theory of directedness. 
(4.18) Sometimes it is said that Newtonian physics is deterministic (in the Hobbesian sense) or that it supported belief in determinism. The opposite is true. Newtonian physics describes superposition, which means that forces can co-operate so that the resulting force acts as if only it and not the component forces existed. This entails that each force is open to co-operation with other forces and thus each physical cause is open to co-opereation with other events. Newtonian physics also implies that processes driven by forces can be interfered with. Thus causes that operate through Newtonian forces are never 'sufficient' in the Hobbesian and Leibnizian sense; no events 'exclude' the operation of further factors. Newtonian physics is precisely formulated in terms of forces and not in terms of actual movements because, contrary to determinism, it takes into account that all events and all forces can be counteracted and can co-operate with other events or forces. It does not make statements of the form 'Events of kind $x$ are followed by events of kind $y$,' instead it makes statements of the form 'There are forces of kind $x$ in situations of kind y.' Strictly speaking, it does not entail unconditional predictions but only predictions of the form 'In a state of affairs of type $x$, if nothing else is acting on the things involved, a state of affairs of type $y$ will follow.'

\section{The principle of causal openness re-stated in terms of directedness}

(5.1) Now we can state causal openness in terms of directedness. If $\mathrm{S}_{1}$ was the basis of a directedness towards $\mathrm{S}_{2}$ at $\mathrm{t}_{2}$ and that directedness was realised and thus $S_{1}$ caused $S_{2}$, then something could have prevented $S_{2}$ despite the occurrence of $\mathrm{S}_{1}$, through some event cooperating with $\mathrm{S}_{1}$, through the intervention of a physical process, or through the intervention of an agent. Thus, $\mathrm{S}_{1}$ did not necessitate $\mathrm{S}_{2}$.

That $\mathrm{S}_{2}$ could have been prevented by a cooperating event means that there could have been an event at $t_{1}$ which together with $\mathrm{S}_{1}$ would have formed the basis of a directedness towards towards an event that does not include $\mathrm{S}_{2}$.

That $\mathrm{S}_{2}$ could have been prevented by an intervention of a physical thing means that there could have been a causal process-nonprobabilistic or 
probabilistic - that led to an event $E$ between $t_{1}$ and $t_{2}$ which is incompatible with an event towards which $\mathrm{S}_{1}$ was directed. If in this scenario that process was nonprobabilistic, then there was at $t_{1}$ no resulting directedness towards $S_{2}$ but one towards $E$ that is based on the conjunction of $S_{1}$ plus the basis of the directedness towards E.

That $\mathrm{S}_{2}$ could have been prevented by an intervention of a person means that there could have been an agent-for example an animal, a human, or God - who brings about a choice event between $t_{1}$ and $t_{2}$ which is incompatible with an event towards which $\mathrm{S}_{1}$ was directed.

(5.2) Hobbes, Kant and many others believed that a physical event can occur only by being necessitated by preceding physical events. This demonstrates that if one believes $\mathrm{p}$ strongly, then one can come to believe that $\mathrm{p}$ is evident and obvious while in fact $\mathrm{p}$ is not evident or even false. When quantum mechanics was discovered and showed that probabilistic processes are at least possible that was a shock for those who believed in determinism. Confronted with quantum mechanics, the belief that a physical event can occur only by being necessitated by preceding physical events was replaced by the belief that an event can occur only by either being necessitated by preceding physical events or by being the result of a probabilistic process. But there is a third way of how an event can occur-and the first way is not a possibility. The most obvious possibility of how an event can occur seems to me to be: An event can occur as the result of a causal process which is not probabilistic but which can be stopped.

But we can imagine more ways how an event can come to occur, for example an event can occur as the result of a probabilistic process (that is, through a probabilistic directedness), or an event can occur through the action of a person so that the event has no preceding cause.

(5.3) To summarise: Physical causes are open to cooperation with other physical events and to counteraction by any possible causes, including physical things, souls, and God. Therefore a physical event cannot necessitate a later event, and it cannot exclude that something intervenes and prevents an event that it would have caused had nothing counteracted. Arguments from causal closure against souls acting on the body, against persons stopping causal processes or initiating causal processes through free actions, and against divine interventions require a modal 
version of $\mathrm{PCC}$, they need to claim that it is impossible that a physical event is not necessitated by preceding events. Arguments from causal closure fail because it is impossible that an event is necessitated by a preceding event. Whether there are souls, free actions, or divine interventions we can find out not by considering some general principle or modal truth but only by investigating the evidence.

\section{Acknowledgements}

I am grateful to the John Templeton Foundation for funding this research in the project 'The Openness of the Universe for Free Will and Special Divine Action, ID 59226.

\section{References}

Bramhall, John. 1655 [1844]. "A Defence of True Liberty from Antecedent and Extrinsical Necessity." In Works, vol. 4, 23-196. Oxford.

Crusius, Christian August. 1743. De usu et limitibus principii rationis determinantis vulgo sufficientis. Leipzig.

Gibb, Sophie. 2015. "The Causal Closure Principle." Philosophical Quarterly 65 (261): 626-47. https://doi.org/10.1093/pq/pqv030

Hobbes, Thomas. 1654. "Of Liberty and Necessity." In The English Works of Thomas Hobbes of Malmesbury. Vol. 4, edited by W. Molesworth, 229-78. London.

Hobbes, Thomas. 1655. "Concerning Body." In The English Works of Thomas Hobbes of Malmesbury. Vol. 1: Elements of Philosophy, edited by W. Molesworth. London.

Kim, Jaegwon. 1996. Philosophy of Mind. Westview Press.

Kim, Jaegwon. 1998. Mind in a Physical World: An Essay on the Mind-Body Problem and Mental Causation. Cambridge, MA: MIT Press.

Kim, Jaegwon. 2005. Physicalism, or Something near Enough. Princeton: Princeton University Press.

Lowe, E.J. 2008. Personal Agency: The Metaphysics of Mind and Action. Oxford: Oxford University Press. https://doi.org/10.1093/acprof:oso/9780199217144.001.0001

Massin, Olivier. 2017. "The Composition of Forces." The British Journal for the Philosophy of Science 68 (3): 805-46. https://doi.org/10.1093/bjps/axv048

Menzies, Peter. 2015. "The Causal Closure Argument is No Threat to Non-Reductive Physicalism." Humana Mente 8 (29): 21-46. 
Montero, Barbara. 2003. "Varieties of Causal Closure." In Physicalism and Mental Causation: The Metaphysics of Mind and Action, edited by Sven Walter and Heinz-Dieter Hackmann, 173-87. Exeter: Imprint Academic.

Montero, Barbara Gail, and David Papineau. 2016. "Naturalism and Physicalism." In The Blackwell Companion to Naturalism, edited by Kelly James Clark, 17387. $1^{\text {st }}$ ed. John Wiley \& Sons. https://doi.org/10.1002/9781118657775.ch13

Mumford, Stephen, and Rani Lill Anjum. 2011. Getting Causes from Powers. Oxford: Oxford University Press. https://doi.org/10.1093/acprof:oso/9780199695614.001.0001

Papineau, David. 2009. "The Causal Closure of the Physical and Naturalism." In The Oxford Handbook of Philosophy of Mind, edited by Brian McLaughlin, Ansgar Beckermann, and Sven Walter, 53-65. Oxford: Oxford University Press. https://doi.org/10.1093/oxfordhb/9780199262618.003.0003

Schrenk, Markus. 2010. "The Powerlessness of Necessity." Noûs 44 (4): 725-39. https://doi.org/10.1111/j.1468-0068.2010.00755.x

Wachter, Daniel von. 2003. "How a Philosophical Theory of Causation May Help in Ontological Engineering." Comparative and Functional Genomics 4 (1): 111-14. https://doi.org/10.1002/cfg.258

Wachter, Daniel von. 2009. Die kausale Struktur der Welt. Eine philosophische Untersuchung über Verursachung, Naturgesetze, freie Handlungen, Möglichkeit und Gottes kausale Rolle in der Welt. Freiburg: Alber. https://doi.org/10.5282/ubm/epub.1975

Wachter, Daniel von. 2012. "Kein Gehirnereignis kann ein späteres festlegen." Zeitschrift für philosophische Forschung 66: 393-408. https://doi.org/10.3196/004433012802834909 